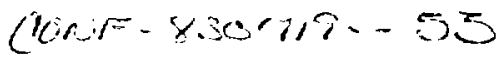

UCRL. 83974

PREPRINT

UCRL- -88974
DE. 000158

SHOCK HUGONIOT MEASUREMENTS

Ofi Ta TO $0.78 \mathrm{TPa}$

K E Froeschner

R S Lee

H Hi Chau

R C Weingart

\title{
Proceedings of the American Physical Society
}

1983 Topical Conference on

Shock Wayes in Condensed Matter

Santa Fe, New Mexico

August 18,1983

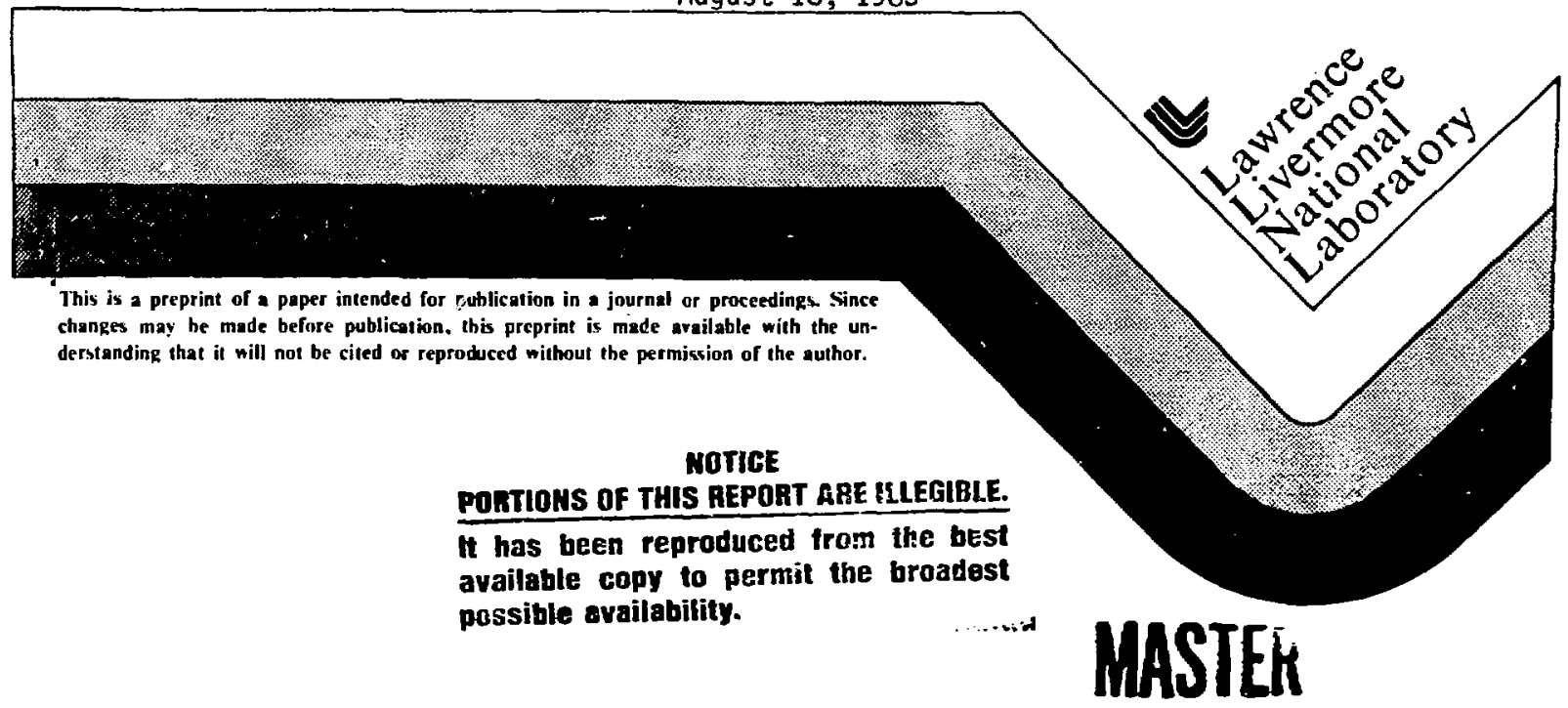




\section{DISCLAIMER}

This report was prepared as an account of work sponsored by an agency of the United States Government. Neither the United States Government nor any agency thereor, nor any of their employes, makes any warranty, express or implied, of assumes any legal liability or responsibility fot the sccuracy, completeness, or usefulness of any information, apparanus, product, or process disclosed, or represents that its use would not infringe privately owned rights. Refer. ence herein to any sperific commercial product, process, or service by trade name, trademark, manufacturer, or otherwise does not necessarily constitute or imply its endorsement. recom. mendation, of favoring by the United States Government of any agency thereof. The views and opinions of authors expressed berein do not necessarily state or reflect those of the United States Governmest or any agency theroor. 


\title{
SHOCK HUGONIOT MEASUREMENTS ON TO TO 0.78 TPa
}

\author{
K. E. Froeschner
}

Martin, Froeschner 8 Associates, under co: Itract to Lawrence Livermore National Laboratory

$$
\text { R. S. Lee }
$$

Department of Physics, Kansas State University, Manhattan, Kanses

\author{
H. H. Chau, R. C. Weingart
}

Lawrence Livermore Nationsl Laboratory

Livermore, California

\begin{abstract}
Symnetric impact shock Hugoniot measurements have been made on Ta with an electrically expladed foil gun system. The results obtained to date for the Hugoniot of Ta auver the range 0.19 to $0.78 \mathrm{TPa}$ (impact velocities from 4.0 to $9.7 \mathrm{~km} / \mathrm{s}$ ) and agree with data obtained by other researchers to within $2.7^{\circ} \mathrm{rms}$. Recent improvetnents in the system include electromegnetic shielding of inpactor and tanget, continuous measurement of impactor velocity with a Fabry-Perot interferometer and
\end{abstract} computer-aided analysis of shot film.

Conservative extrapoiation from current operating conditions indicate that pressures of 1.1 to I.5 TPa could be achieved with hittle difficulty.

\section{Introduction}

To understand and predict the behavior of material at extremely hugh pressure it is necessary to know its equation of stule (EOS) in the appropriate regime. One important aspect of the EOS of any material is its shock Hugoniot, the locus of points in thermodynamic state spuce which can be reached by a single instantaneous compression, i.e., a shock wave. Knowledge of the shock liugoniot is especially important in research areas where energy densities and velocities are high such as astrophysics, planetary scicnee studies, meteorite impacts, ".sapon design, military systems vulnerability and high explosive engineering.

Using the well-known Rinkine-Hugoniot relations expressiris conservation of mass, momentum and energy across a strock front, a point on the Hugoniot of a material may be completely specified by measuring only two state viriables. For instance, if the shock propispation velocity, $u_{s}$, and the material velocity behi no the shock, $u_{m}$, are both measured, then the pressurc, compression, density, and specific internal energy in the shocked state are given by:

$$
\begin{aligned}
& P=P_{0}+D_{0} u_{s} u_{m} \\
& n=z / D_{0}=u_{s} /\left(u_{s}-u_{m}\right) \\
& E=E_{0}+1 / 2\left(P+P_{0}\right)\left(P_{0}^{-1}-D^{-1}\right)
\end{aligned}
$$

Many experimental teehniques and devices have been devised over the years to measure points on the shock llugonot. The classic technique is to accelerate a thin plate of the sample material into a target of the same material. When the impactor plate collides with the target plate a steady, one-dimensional shoek is produced which propagates through the target and back into the impactor. The velocity of propagation of this shock in the tanget, $u_{s}$, is determined by measuring the time of breakout at the front surface of the target on either side of a step, which has been cut into the front surface of the target. The material velocity can be shown by symmetry considers ions to be exactly one-b-aif the bulk velocity of the impactor at the instant of impact, i.e., $u_{m}=1 / 2 u_{i}$, and the im can be meesured by a variety of techniques. Methods which have been used to accelernte the impactor plate include high explosives in simple and onmpound systems, single and two-stage gas guns, rail gius, and rass drivers. In the work described in this paper, the impactor is driven by the electrical explosion of a metallic foil in a device which we call an "Electrie Gun".?

Other techniques have been employed which do not direetly measure a point on the Hugoniot of the ssimple material because they measure only one thermodynamic variable, usually the shock velocity, $u_{s}$ Useful information ean be obtained in such systems through the technique of "inpedance inatehing" provided that ancther material with known EOS is included in the experiment. ${ }^{2}$

\section{The LLNL Electric Gun}

The highest laboratory pressure achi evable in uranium with eurrent two-stage ges guns is ebout $500 \mathrm{GPa} .^{5}$ Most metals have equat ions of state which are relatively simple in this pressure regime. A linear relationship bet ween the shock and material velocitips characterizes 
the shock Itugonior, i.c., $u_{s}=0_{0}+5 u_{m}$. At extremely high pressures, the equation of state cun be aceurutely calculated from theoretical models bused upon the methods of stetistical plysics.

The repton from $0.5 \mathrm{TPa}$ to several TPa is where the lurgest uncertainties in EOS exist. A proinising technolagy we have developed at LLNL to explore this region is the clectric gun.

In an electrie gun, an impuctor (projectile) -usually a thin foil or a composite of several foils- is accelerated to a high velocity when an adjacent metal foil is electreally exploded by rapid Joule heating (Fig. 1). then the foil explodes, it punches out a section of the impactor unn drives it up an evacuated barrel to strike the target.

The energy density achievable in the exploding foil is many times that obtained with chemical high

explosives. Mloreover, intense inagnetic fields generated by the currents flowisg in the foil plasms and rear conduetor inpart a substantial additional acceleration (Lorenz acceieration) to the impactot. As a result, the projectule may be acceleruted to velocities well beyond the reach of other technologies. The fastest slcetriçiun system in use at LINL has cecelerated plastic projectiles $0.3 \mathrm{~mm}$ thick and $8 \mathrm{~mm}$ in diameter lo a velacity of $30 \mathrm{~km} / \mathrm{s}$ and composite plastic-Ta projectiles of the same diameter to $12.6 \mathrm{~km} / \mathrm{s}$. This eppubitity led us to explore the electric gun's potential as a shock-wave generator in experıments designed to charueterize the EOS of a material at high pressures.

Apart from its eleetrical power souree, the electric gun is an inexpensive, throw-away device that dissipates a telatively small ainount of energy compared to gas puns or high-explosive systems. Because it is self-conteined, it is especially suited to experiments on razandous materials that might otherwise contaminate an expensive and complex research facility.

Although the electric gun is conceotually simple, a nutnber of difficulties arise in applying it to EOS experiments. A substantial part of our researeh has been aimed at identifying and solving such problems as hydrodynanije jetting, target preheat and premotion, impuctor preheat and nonplanarity. Whe have also developed experimental and diagnostic techniques with accuracies suificient to measure impactor velocity and shacl: transit times to 1 or $2 \%$.

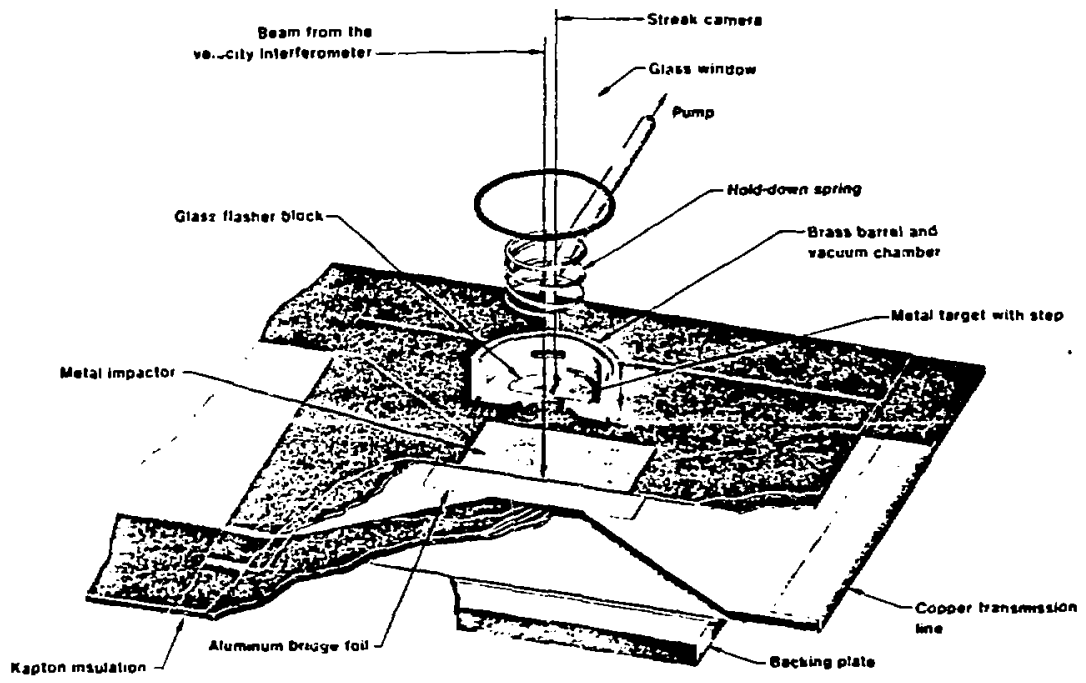

Finure 2. Exploded and partids cutoway vieł of a typical electrac gun Eos expericent. The andctor is accilerated to high velocitu by the electrical explosion of the underiting aluminum bricge foit. Whes the bridge foll explodes, it punches out a section of the impactor ano insulat:ng lavers and drives chen up tial avacuated barzel to strike the taroet. The transisisich line, bidge foit,

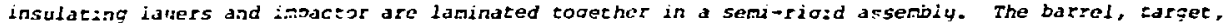
ycuum apparatus and backing afo adifed and the fompiece experiment is placed in an exper:ant

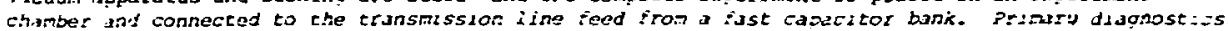

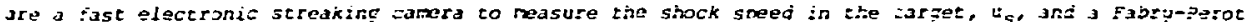

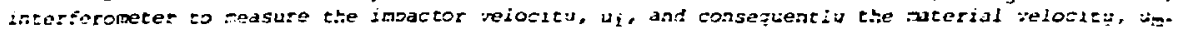


We chose tuntulum as the test mutcrial in these prool-of-conecpt axperiments beeause its F.03 already hus been well churucterized by other ineans.

\section{Desion of the Eleetric-Gun EOS Experiments}

lie used two different imphetor designs. In the lower-velocity experiments, the design consisted of a rolled-tantalum impuctor foil $76 \mathrm{um}$ thick bonded to hapton bucking to protect it trom the plasma genesated by the exploding ioil. In the high-velocity experiments, the impuctor was a rolled-tantalum foil $30 \mathrm{\mu m}$ thick. We found thut the thinner foils used in the high-velocity experiments ware more sensitive to preheating by stray electric currents and rapidly shanging magnetic fields. To protect them from preheatirg, we bonded the hi sh-velocity foils to a kapton-aluminum-Kapton sandwich. Both impactor designs were in turn bonded to un aiuminum exploding foil.

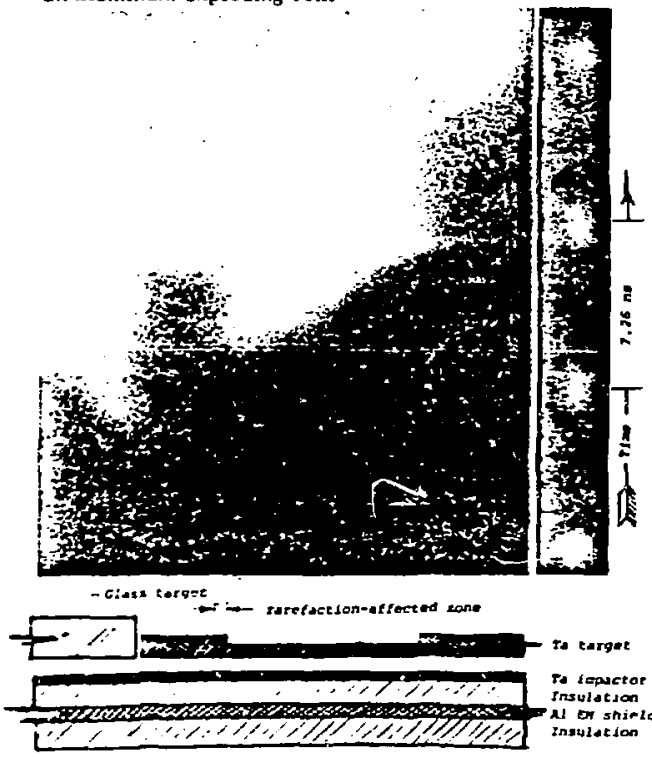

- ioure 2. Finceronic strnak camera record from a tuntoji EOS experiment. The skecch shoivs tice arojeario snd earzers to scale, just prior to innact. Fron the 5 teo in the shock breakout sicnul in oct $u_{5}=8.01 \pm 0.3$ inis. The FabryPerot ressurad $4:=7.79+0,2 \mathrm{~kg} / \mathrm{s}$

The targets consisted of tantalum foils two to three times the thickness of the impuctors. Steps inachined in the front surfuce of the targets enubled us to determine the snock velocity by meusurın shock transit time across an individual siep.

The pritnury diagnostics consisted of t wo imaron image-converter camerss oparated in the streak mode. in one cumers, the slit aperture was aligned over the targel steps and a class Masher block (which produces a tlash of lizht when it is hit and shocked). At pressures of 0.l TPa or more, shock temperatures are high enough to produce thermal light emission that can be deteeted by a Iast streak eamera at the instant of impaet on the plass or when the shock arrives at the free surfaces of the metal target. From tifs recond, we determined the time of sirock ureakout at two different distances through the target. Figure 2 shows typical record from this camera. From the record of the impact on the glass we can determine the Matness and smoothness of the impactor, the presence of debris, ete.

The second camera was used in conjunction with a Fabry-Perot velocity interferometer ${ }^{3}$ to obtain a continuous history of the impactor velocity.

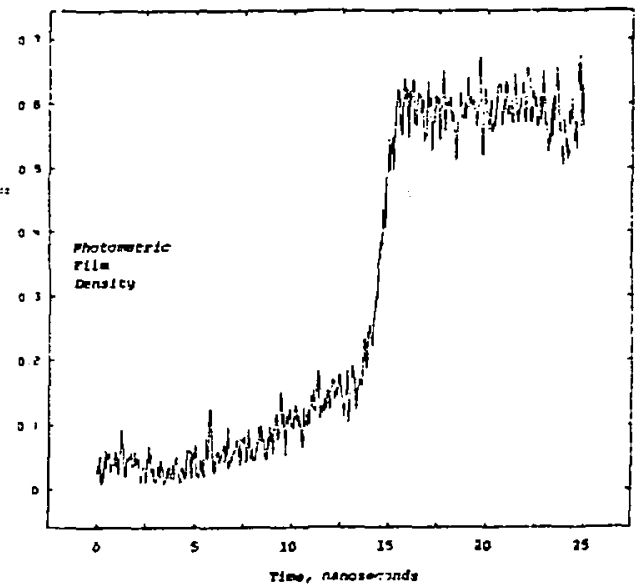

Eigure 3. Rise time of the shock breatout signal. Nower camera designs could decrease the uncertaintu in $u_{5}$ to about 1 t.

We can measure the impactor velocity and consequently the material velocity $u$ to $\pm 1.2 \%$ with the Fabry-Perot interferometer. Ermes in the shock velocity $u_{s}$ result primarily from ercors in measuring the step height of the target (about $\pm 0.6 \%$ ) and from the intrinsic resolution of the canera, from tl to $\pm 5 \%$, dependirg on the camers model and the streaking ratc.

In Fig. 3, we show a microdensitometer trace of the shock breakout sigrul. The rate of rise of the signal is 0.32 density units/ns, and since the film graininess is about $\mathbf{\pm 0 . 0 5}$ density units, the uncertainty in locatins the shock breakout time, i.e., the mid-point on the rising signal is about \pm 0.12 ns.

The sluck transil time over the step distance is about ins in the thin tancets and 10 ns in the thick targets. The uncertainty in the transit time is thus aboul $\$ 37$ in the high pressure thin target data and about $\pm .5 \%$ in the lower pressure thick tanget data.

Departures from planarity of the impuct or and target must be measured and, if they are signifjeant, a 
corsection inus: be mude. The magnitude of this correction is determucd oy the deviution from planarity in the inmediate vieinity of the step in the tanget. In mic usuris the shock trunsit time, a rarefuetion affected zone neir the step nutust be avoided because the shock pressure and speed will be unrepresentative in ifis region. This zene will be froin one to two times the step height, as shovin in Fig. 2. In our EOS experiments, the slep neights are only ubout $30 \mathrm{um}$. Correctiolss for deviations irom plunarity over distances of this onder $(60: m)$ ure very small, on the order of 0.1 ns $m$ id are coinparable to the resolution of the camera system.

In our most accurale expcrinents, the estimeted error in $u_{f n}$ was \pm 1.29 and in $u_{s} \pm 2.5 \%$, leading to ercors of $\pm 2.7 \div$ in pressure and \pm 3.38 in volume.

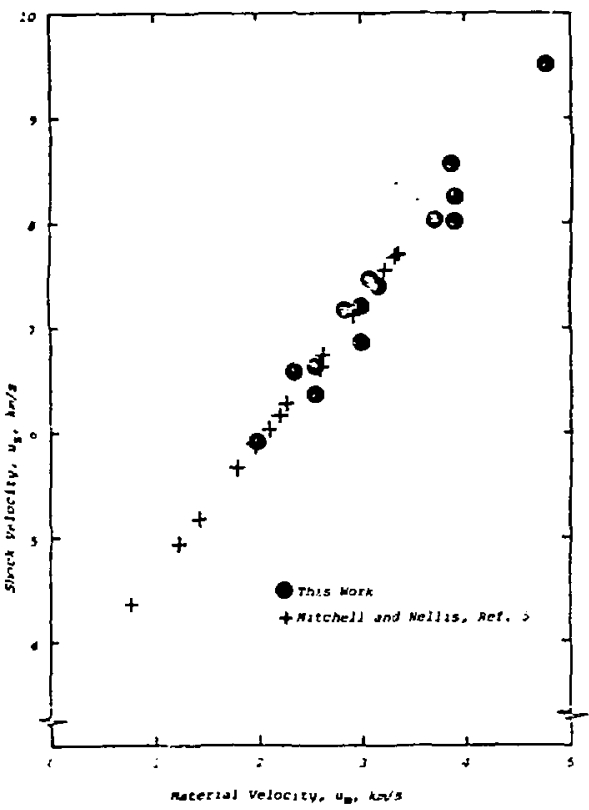

Figure t. The shock Hugoniot of Tantalum.

\section{Experimental Results}

Our earlicst electric-gun results were obtained with relatively thick impactor foils $(76 \mathrm{~mm})$, which reduced iilpact velocities ellough to sllow comparison of our dat a with those reported by others. 4 Our shock Huromot duta agree with those obtained with u two-stuge gas gun up to its performnnee limit, about t.ju CPPu.J as is sloown in FIg. 4.

ilore recent experiments used thinner $(30 \mathrm{um})$ tantalum impuetors and achieved velocities up to $9.7 \mathrm{~km} / \mathrm{s}$, extending the Hugonide curve for tuntalum up to $780 \mathrm{rPa}$. All of our data iall within 2.7 s root-ineansquare of a straght line fit to the gas-gun data.

\section{Cunclusions}

We have established the feasibility of making direct ultra-tigh pressurc ineasurements of the shoek Hugoniots with the electrie gun. We have reduced experimental uneertainties to $\pm 1.2 \%$ in $u_{n}$ and $\pm 2.5 \%$ in Us und have reproduced existing data to within expurimental error.

Conservutive extrupolations from our system's eurrant operating conditions indicate thet pressures of from l.1 to 1.5 TPa could be achieved in various dense materials with little difficulty. ${ }^{6}$ Tr - extremely high velocities we have uehieved with plastic impactors lead us to believe that even higher pressures cun be reached.

\section{References}

l. H. H. Chau, G. Dittbenner, W, w. Hofer, C. A. Honodel, D. J. Steinberg, J. R. Stroud and R. C. Weingart, The Electric Gun: A Versatile Tool for High Pressure Shoek Wave Research, Rev. Sei. Instruin, 51, 0028 (1980).

2. C. E. Ragan I11, Shock Compression Measurements at 1 to ? TPa, Physical Review A, 25 No. $\overline{0}, \mathrm{P} .33 \hat{6} 0$.

3. D. R. Goosman, et al, Measuring Velocities by Laser Doppler Interferometer, LLNL Energy and Technology heview, UCRL-52000-79-3, Harch 1979.

4. K. E. Froeschner, et al, Shock Hugoniot Measurements Using an Electric Gun, in Shock Waves in Condensed Matter - 1981, AIP Conference Praceedings No. 73, p. 174.

5. A. C. Mitchell and W. J. Nellis, J. Appl. Phys. $\underline{52}$ 3363 ( $\mid 9 B !)$.

6. LLNL, Encrgy and Technology Review, UCRL-52000-8\&-12, Dec. 1982, p.11.

\section{DISCLAIME:}

This Jocument was prepared as an account of work sponsored by an ageney of the United States Government. Nejther the United States Government nor the University of California nor any of their employee: makes any warranty, express or implied, or assumes any legal lisoility or responsibility for the accuracy, cumpleieness, or usefulness of any information, appurat's, product, or process disclosed, or represents that its ise would not inf rif re privately owned rights. Reference herein to any specific commercial products, process, or service by trade numes, trademark, manufacturer, or stherwise, does not necessarily constitute or imply its eridorsement, recominendution, or favoring by the United States Governinent of the Universily of Califoria. The vicws and opinions of authors expressed herein do not necessanly state or reflect those of the United States Covernment thereor. and shall not be ised for advertizing or proguct endorsement purposes.

"Work performed under the auspices of the lis. Lepartinent of Energy by the Lawrence Livermore vationsl Labnratory under cuntruct number N-7 JOS-ENG-48" 